\title{
The Future of Red Cell Transfusion Lies in Cultured Red Cells
}

\author{
Rizwan Javed $^{1}$ [D Lorraine Flores $^{2}$ Saurabh Jayant Bhave ${ }^{1} \quad$ Asheer Jawed $^{3}$ Deepak Kumar Mishra ${ }^{4}$
}

1 Department of Clinical Haematology and BMT, TATA Medical Center, Kolkata, West Bengal, India

2 Department of Histocompatibility and Immunogenetics, NHS Blood

Address for correspondence Rizwan Javed, MD, Department of Clinical Hematology \& Cellular Therapies, Kolkata, West Bengal and Transplant, Filton, Bristol, United Kingdom

${ }^{3}$ Department of Respiratory Medicine at William Harvey Hospital, Ashford, United Kingdom

${ }^{4}$ Laboratory Haematology, TATA Medical Center, Kolkata, West

Bengal, India

Ind J Med Paediatr Oncol 2021;42:528-532.

\begin{abstract}
Keywords

- cultured red cells

- BELA-A2 cells

- clinical significance

Blood is a very important resource for healthcare-based services and there has been a consistently increasing demand for it in most parts of the world. Poor volunteer-based collection system, high-risk of transfusion-transmitted infections, and emergence of new pathogens as evident from the ongoing Coronavirus Disease 2019 (COVID-19) pandemic are potential challenges to the global healthcare systems. It is imperative to explore safe and reliable alternatives to red cell transfusions. Ex vivo culture of red cells (CRBCs) from different sources such as hematopoietic stem cells (HSCs), pluripotent stem cells, and immortalized progenitors (e.g., BELA-2 cells) could revolutionize transfusion medicine. CRBC could be of great diagnostic and therapeutic utility. It may provide a backup in times of acute shortages in patients with rare blood groups, and in cases with multiple antibodies or sickle cell anemia. The CRISP-Cas9 system has been used to develop personalized, multi-compatible RBCs for diagnostic reagents and patients with multiple allo-antibodies. CRBC could be practically feasible for pediatric patients, who require small quantities of red cell transfusions. CRBC produced under good manufacturing practice (GMP) conditions has been reported to survive in human blood circulation for more than 26 days. Recently, a phase I randomized controlled clinical trial called RESTORE was initiated to assess the survival and recovery of cRBCs. However, feasible technological advancement is required to produce enough cRBCs for clinical use. It is crucial to identify sustainable sources for large-scale production of clinically useful CRBCs. Although the potential cost of one unit of CRBC is extrapolated to be around US\$8000, it is a life-saving product for patients having rare blood groups and is a "ready to use" source of phenotype-matched, homogenous young red cells in emergency situations.
\end{abstract}

DOI https://doi.org/ 10.1055/s-0041-1740068. ISSN $0971-5851$.

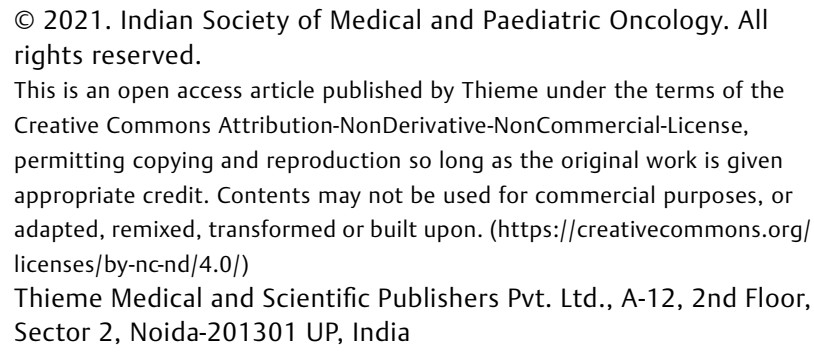

(C) 2021. Indian Society of Medical and Paediatric Oncology. All rights reserved.

This is an open access article published by Thieme under the terms of the Creative Commons Attribution-NonDerivative-NonCommercial-License, permitting copying and reproduction so long as the original work is given appropriate credit. Contents may not be used for commercial purposes, or adapted, remixed, transformed or built upon. (https://creativecommons.org/ licenses/by-nc-nd/4.0/)

Thieme Medical and Scientific Publishers Pvt. Ltd., A-12, 2nd Floor, Sector 2, Noida-201301 UP, India 


\section{Introduction}

Blood is a very important resource for healthcare-based services. Although the demand profile varies in different parts of the world, there has been a consistently increasing demand for blood. In the developed world, the increase in the demand is attributed to longer life expectancy and increase in complex medical procedures, arising from cardiovascular surgeries and oncology treatments, whereas the common causes of red cell transfusion in the developing world are post-partum hemorrhage and severe childhood anemia. The high risk of transfusion-transmitted infections and emergence of new pathogens (such as severe acute respiratory syndrome coronavirus 2 [SARS-CoV-2]) has compounded the problem of safe blood supply shortages. ${ }^{1}$ The World Health Organization (WHO) Factsheet 2013 reveals that despite 112.5 million blood donations globally every year, there are around 100,000 deaths annually in the developing countries due to unmet transfusion needs of pregnant women alone. ${ }^{2}$ Poor volunteer-based collection system in developing nations and problems with transient supply shortages in the developed world are potential challenges to the global healthcare systems. It is imperative to explore safe and reliable alternatives to red cell transfusions. ${ }^{3}$

We aimed to review the current literature on cultured red cells and its possible clinical applications.

\section{Methodology}

PubMed and Google databases were searched for effective methods of red cell cultures and its possible future clinical use. The keywords used for literature search included red cell cultures, BELA-A2 cells and transfusion. Reference lists were cross-checked for relevant citations, and more searches were undertaken until the desired information was obtained.

\section{Cell Cultures}

Ex-vivo red cell cells (cRBCs) could revolutionize transfusion medicine. cRBCs could be derived from different sources such as hematopoietic stem cells (HSCs), immortalized progenitors and pluripotent stem cells. cRBCs could provide a crucial backup during acute shortages in rare blood groups and in cases with multiple antibodies. It is imperative to identify reliable, safe, and sustainable sources for large-scale production of clinically useful cRBCs.

\section{Normal Hematopoiesis}

Normally, the HSCs differentiate into a common myeloid lineage, megakaryocyte-erythroid precursors, and subsequently to erythroid precursor cells such as burst-forming units (BFU-E) and colony-forming units (CFU-E). ${ }^{4}$ The use of erythropoietin is essential for the multiplication of erythroid progenitors making them sensitive to the effect of other growth factors during hematopoiesis. It takes 7 days for the CFU-E to proliferate and differentiate into mature erythroblasts. $^{5}$ In the presence of cytokines, erythropoiesis progresses with the development of proerythroblasts,

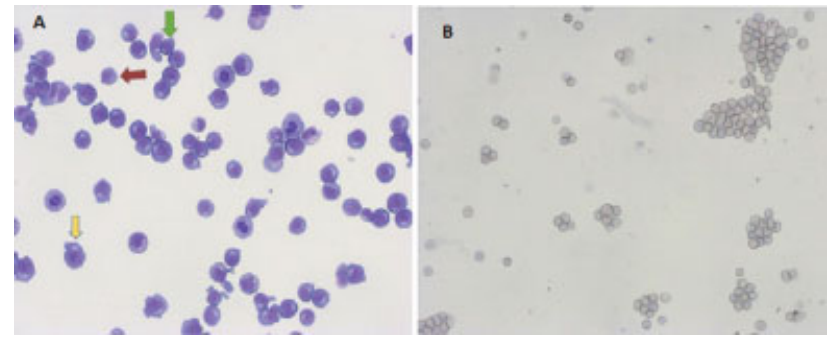

Fig. 1 (A) Microphotograph of erythroid cultures showing proerythoblasts (yellow arrow), basophilic erythroblasts (green arrow), and polychromatic erythroblasts (condensed chromatin with gray-blue cytoplasm, red arrow) on Day 7 (20x, Giemsa stain). (B) Microphotograph showing reticulocytes in clusters and discreet after filtration of erythroid cultures (20x, Giemsa).

followed by basophilic to polychromatic erythroblasts, and finally to orthochromatic erythroblasts that enucleate into reticulocytes ( $\mathbf{\text { Fig. 1 } ) .}{ }^{6}$ Toward the terminal differentiation, the expelled nucleus of the erythroblasts is phagocytosed by macrophages. Presently, laboratory scientists are exploring multiple ways to replicate hematopoiesis in vitro.

\section{Liquid Culture Methods}

Hematopoiesis was initially studied on a semisolid culture medium, but it was difficult to quantitatively analyze the growth kinetics, and biochemical and immunological characteristics of immobilized developing cells. Fibach et al developed the two-step liquid cultures to study erythroid cell development. ${ }^{7}$ In the first step, erythroid progenitors from the umbilical cord and adult peripheral blood were amplified using medullary microenvironment, comprising stromal cells, and subsequently, these cells underwent maturation. ${ }^{6}$ Douay et al did several studies under well-defined conditions to amplify stem and progenitor cells from cord blood. ${ }^{8-10}$ Thereafter, several researchers developed a modified cocktail of cytokines called SED, which comprised stem cell factor (SCF), erythropoietin (EPO), and dexamethasone. This cocktail helped induce the growth of progenitors cells and their differentiation into stress erythroblasts. The appearance of stress erythroblasts is usually seen during major blood loss and are considered the first line of defense. ${ }^{11-13}$ Migliaccio et al modified the SED cocktail to cause massive amplification of cRBCs that had antigens similar to human RBCs in vivo. ${ }^{14-16}$ Lately, self-renewing erythroblasts were isolated from early mouse embryos. These primary erythroid precursors extensively proliferated ex vivo on exposure to SED cocktail $\left(10^{6}\right.$ to $10^{60}$-fold) and have renewed interest among scientists to search for similar cells in humans. It is believed that these self-renewing erythroblasts could serve as a potential semi-permanent source of cRBCs in the future. ${ }^{17}$ Based on the number of media stages ( 2 to 4 ), culture systems could be classified and their difference lies in the addition and subtraction of several cytokines ( - Table $\mathbf{1}$ ). In general, the primary stage causes the expansion of HSCs in the presence of EPO, SCF, and interleukin-3 (IL-3). In the secondary stage, cytokines such as SCF, EPO, and transferrin cause secondary expansion of erythroblasts. EPO and 
Table 1 Types and contents of culture media for erythroid cells

\begin{tabular}{|l|}
\hline Primary Medium \\
\hline $\begin{array}{l}\text { Iscove's modified Dulbecco's media (IMDM) with glutamine, } \\
\text { SCF, IL-3, EPO, AB serum, insulin, heparin, holotransferrin, } \\
\text { and }\end{array}$ \\
\hline HAS \\
\hline Secondary Medium \\
\hline As primary media excluding IL-3 \\
\hline Tertiary Medium \\
\hline As primary media excluding IL-3 and SCF \\
\hline
\end{tabular}

Abbreviations: AB; EPO, erythropoietin; HAS; IL, interleukin; SCF, stem cell factor.

holotransferrin are responsible for the terminal differentiation. Several other cytokines such as IL-6, thrombopoietin (TPO), and Feline McDonough Sarcoma (fms)-like tyrosine kinase 3 (Flt-3), along with glucocorticoids ${ }^{18}$ could be added to the first stage to facilitate the expansion before the differentiation. Researchers have also found that early erythroid progenitors self-renew in the presence of glucocorticoids, along with many agonists such as prolyl hydroxylase inhibitors, ${ }^{19}$ transforming growth factor $\beta$ (TGF- $\beta$ ), and peroxisome proliferator-activated receptor $\alpha$ (PPAR-a). ${ }^{20,21}$

\section{Growth Curves of cRBC}

Normally, cRBCs show a typical sigmoid pattern of proliferation. The hematopoietic progenitors undergo a lag phase, in which the cells do not divide but adapt to the culture conditions. $^{22}$ Lag phase is followed by logarithmic (log) growth phase, characterized by active proliferation and exponential increase in cell density and eventually the cells enter the stationary or plateau phase, which reflects the slowing down of cell proliferation as they become confluent (-Fig. 2). The initial progenitors could be derived from the sources ( - Fig. 3 ) discussed below.

Circulating HSCs and progenitor cells derived from healthy human donors and cord blood collections have successfully been cultured. This could be very useful to

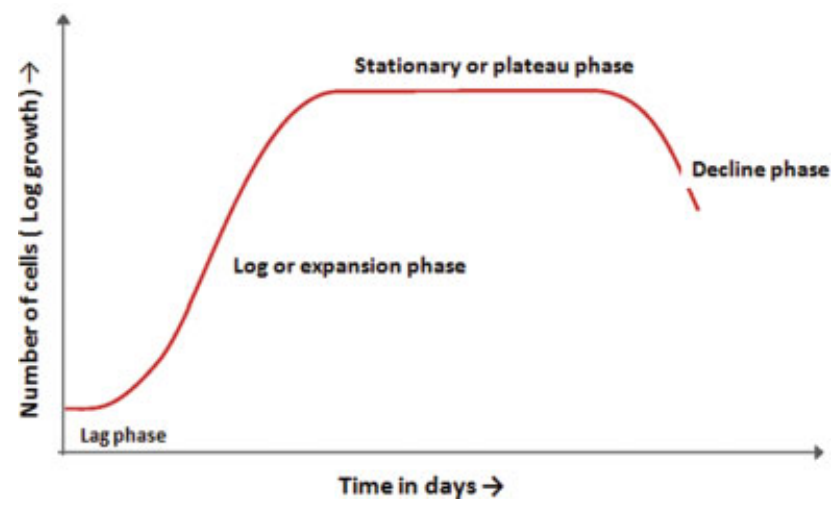

Fig. 2 The growth curves showing the cumulative increase of erythroid cell cultures (number of cells in the $y$-axis) over the a period of time (days) on the x-axis.

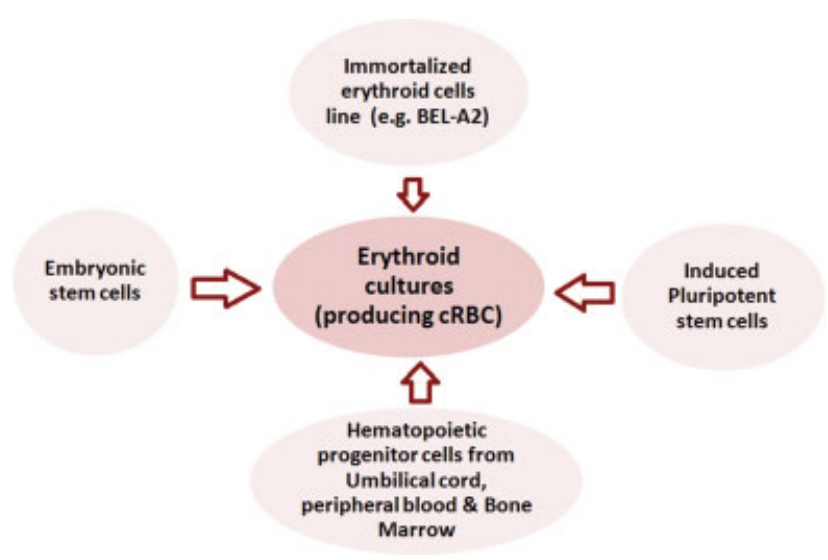

Fig. 3 Methods of generating CRBCs. cRBC, culture of red blood cells.

expand the blood supply of rare blood groups. Theoretically, HSCs in a single unit of cord blood could be amplified to make 500 units of RBCs. Because circulating HSCs and progenitor cells have limited proliferative potential, the production of CRBCs depends on a donation-based collection system. The testing of these cells for transfusion-transmitted infections increases the cost and does not completely eliminate the risk of emerging pathogens. ${ }^{6} \mathrm{cRBC}$ also have a short half-life; it is required to further optimize the culture conditions. Another drawback of these primary cultures is their genetic variability that influences their growth patterns.

Immortal cells such as pluripotent stem cells (human embryonic stem cells [hESCs]) and induced pluripotent stem cells (iPSCs) can also differentiate into erythroid lineage using human feeder layers. Feeder cells derived from a human or animal source do not divide themselves but allow unlimited proliferation of other cells by secreting growth factors. Genetic engineering and xenobiotic-free method could expand the use of these cells in future. ${ }^{6}$

\section{Immortalized Erythroid Cell Line BEL-A2}

Early adult erythroblasts are immortalized to produce a stable cell line, which generates an unlimited supply of CRBCs. Immortalized progenitors are currently the focus of research in transfusion medicine as they could be cultured in relatively simple media. On induction, these cells have the potential to differentiate into cRBCs. ${ }^{6}$ Trakarnsanga first reported the human immortalized cell line called Bristol erythroid line adult (BEL-A2). ${ }^{3}$ The advantage of BEL-A2 is that it avoids long differentiation time (unlike pluripotent stem cells) and does not require constant donations (unlike umbilical cord blood or peripheral blood stem cells). BEL-A2 cells were created using the Tet-inducible human papilloma virus-16-E6/E7 expression system. Their origin lies in CD34 cells of the adult human bone marrow that were cultured for 4 days in a primary medium for erythroid cells. E6 and E7 protein expression was induced using doxycycline on the fifth day. In continuous culture, the doubling time of BEL-A2 cells was 20 hours after Day 100. The cells underwent normal erythropoiesis and showed no functional or molecular difference to ex vivo cultured reticulocytes ( - Fig. 1). However, 
enucleation of BEL-A2 cells into mature reticulocytes is around $30 \%$, which is far from optimum. ${ }^{3}$

Whole exome sequencing (WES) has been done to analyze BEL-A2 genotype, particularly genes associated with blood groups and enucleation. Based on the WES data, blood group phenotypes were correctly predicted and showed concordance with serological results. ${ }^{3,23}$ The WES data of BEL-A2 could be used for manipulating blood group-related genes by gene editing strategies (such as CRISPR-Cas9). In future, antigen-edited red cells could be of diagnostic utility in transfusion laboratories, and rare blood group cells could be expanded for therapeutic purposes. ${ }^{23}$

\section{Large-Scale Production of CRBCs}

In 2011, the transfusion of cRBCs was proven in principle by Giarratana et al, who produced these cells under good manufacturing practice (GMP) conditions and labeled them with ${ }^{15} \mathrm{Cr}^{8}$ It was observed that 40 to $60 \%$ of the cRBCs remained in the blood circulation of healthy human volunteers on Day 26 after injection comparable to the half-life (28 days) of native RBCs. It has been reported that purified cRBCs could be stored for 4 weeks at $4^{\circ} \mathrm{C}$ in Sg-M (saline adenine glucose mannitol)-based solutions. ${ }^{8}$ Recently, the University of Bristol and the University of Cambridge have initiated a clinical trial called RESTORE involving cRBC. It is a phase I, randomized controlled crossover trial among healthy human subjects to assess the survival and recovery of $\mathrm{CRBC} .^{24}$ Although there has been some progress in CRBC production, it would require feasible technological advancement to produce enough cRBCs for clinical use. Presently, more than $1000 \mathrm{~L}$ of medium is required to produce 1 to $2 \times 10^{12}$ cells, contained in a unit of blood. ${ }^{6}$ Bioreactors are being employed for scaling up cRBC production. ${ }^{25}$ Bioreactors mimic hematopoietic microenvironment with biomimetic materials having a continuous perfusion conditions as in the bone marrow. In a bioreactor, an artificial niche comprises a scaffold macroporous structure (polymer matrix), and mesenchymal stem cells are created and subsequently, HSC seeding is done. The conventional twodimensional (2D) culture system is being replaced by a 3D reactor, which could maintain HSCs for a longer period of time, and hence, optimize large-scale CRBC production to $10 \mathrm{~L}$ in 3 to 4 weeks per reactor. ${ }^{26}$

\section{Clinical Significance of CRBCs}

In the near future, cRBCs could be used to manufacture reagent RBC cell panels of known antigen profile used for testing patient serum having unknown antibodies. Present cell panels mostly cover antigen profile of Caucasians; hence these lack greater diversity of antigens to detect uncommon African and Asian phenotypes. Thus, the availability of these reagent RBC panels could greatly improve transfusion services for multi-transfused patients, likely to have multiple alloantibodies. Multiple blood transfusions often lead to alloimmunization caused by incompatibities at several minor blood group antigens. Hawksworth et al has demonstrated the use of gene-editing strategies on immortalized
Table 2 Advantages of cRBCs

\begin{tabular}{|l|}
\hline - cRBC are homogenously young and have a longer life span \\
than native RBCs (heterogeneous in age)
\end{tabular}

erythroid cell line using the CRISP-Cas9 system to knockout several antigen coding genes and generate null phenotype red cells. Hence, these personalized, multi-compatible RBCs could be potentially used for diagnostic reagents and patients with multiple allo-antibodies. ${ }^{27}$

Rare RBC phenotypes lack high-frequency antigens on their surfaces and sometimes, characterized by the presence of antibodies against these antigens (e.g., Bombay blood group or $\mathrm{p}$ phenotype of $\mathrm{P}$ blood group). Hence, they require only identical rare RBCs for transfusions. The culturing of rare red cell phenotypes could be beneficial to such patients, especially pediatric patients, who require small quantities of red cell transfusions. ${ }^{28}$ The application of cRBCs could be extended to antigen-negative red cell units for patients with multiple antibodies or sickle cell anemia. In hemoglobinopathies, it is preferred to transfuse RBCs of a prolonged life span to reduce the frequency of transfusions. Improvements in culture techniques help generate $C R B C s$ having a long life span that could be used in patients ( $\mathbf{- T a b l e ~} \mathbf{2}$ ).

Because storage lesions of RBCs adversely affect the morbidity and mortality in intensive care patients, it is postulated that RBCs generated under completely standardized conditions are metabolically stable and would considerably reduce storage lesions. ${ }^{29}$ It is believed that cRBCs would be deficient in leukocytes and related cytokines; hence it would greatly reduce the risk of transfusion reactions such as non-hemolytic febrile reactions and TRALI (transfusion-related acute lung injury).

\section{Cost of CRBC Units}

Several studies have extrapolated the cost of producing 1 unit of $\mathrm{CRBC}$ to be around US\$ 8000. Although the price of cRBCs is exorbitant, there is an ongoing debate in the developed world to invest in a life-saving product for patients having rare blood groups or those with multiple allo-antibodies. Ready to use cRBC units, having a homogenous population of young red cells, could obliterate the need for frequent transfusions and frantic searches for phenotypematched blood in emergency situations. ${ }^{30,31}$ 


\section{Conclusion}

cRBCs have the potential of revolutionizing transfusion medicine, as these generate a reliable supply of homogenous RBC concentrates having a selected phenotype, with a long life-span and free of leukocyte contamination. If clinical trials have a favorable outcome, the routine use of cRBCs is expected to overcome engineering and economical hurdles. The reality of cRBCs would materialize in the clinics, if technological advancements takes place in a time-bound and cost-effective manner.

\section{Authors' Contributions}

Rizwan Javed and Deepak K. Mishra contributed to conceptualization of the study. Lorraine Flores and Saurabh Jayant Bhave contributed to the design of the study. Saurabh Jayant Bhave and Asheer Jawed defined the intellectual content. Rizwan Javed, Asheer Jawed, and Lorraine Flores contributed to literature research. Rizwan Javed contributed to manuscript preparation. Lorraine Flores, Asheer Jawed, and Deepak K. Mishra contributed to manuscript editing. Saurabh Jayant Bhave, Asheer Jawed, and Deepak K. Mishra contributed to manuscript review.

\section{Funding}

We would like to thank the Commonwealth Scholarship Commission in UK, London, and University of Bristol for funding the training of the first author in Transfusion and Transplantation Sciences (including studies on red cell cultures) at NHS Blood and Transplant at Filton.

\section{Conflict of Interest}

None declared.

\section{References}

1 Seghatchian J. The secrets of human stem cell-derived transfusable RBC for targeted large-scale production and clinical applications: A fresh look into what we need most and lessons to be learned. Transfus Apheresis Sci 2020;59(04):102862

2 World Health Organization (WHO) Factsheet 2013. https://www. who.int/gho/publications/world_health_statistics/2013/en/ Accessed February 2, 2020.

3 Trakarnsanga K, Griffiths RE, Wilson MC, et al. An immortalized adult human erythroid line facilitates sustainable and scalable generation of functional red cells. Nat Commun 2017;8:14750

4 Hebiguchi M, Hirokawa M, Guo YM, et al. Dynamics of human erythroblast enucleation. Int J Hematol 2008;88(05):498-507

5 Ubukawa K, Guo YM, Takahashi M, et al. Enucleation of human erythroblasts involves non-muscle myosin IIB. Blood 2012;119 (04):1036-1044

6 Bouhassira EE. Concise review: production of cultured red blood cells from stem cells. Stem Cells Transl Med 2012;1(12):927-933

7 Fibach E, Manor D, Oppenheim A, Rachmilewitz EA. Proliferation and maturation of human erythroid progenitors in liquid culture. Blood 1989;73(01):100-103

8 Giarratana MC, Kobari L, Lapillonne H, et al. Ex vivo generation of fully mature human red blood cells from hematopoietic stem cells. Nat Biotechnol 2005;23(01):69-74

9 Douay L, Giarratana MC. Ex vivo generation of human red blood cells: a new advance in stem cell engineering. Methods Mol Biol 2009;482:127-140
10 Neildez-Nguyen TM, Wajcman H, Marden MC, et al. Human erythroid cells produced ex vivo at large scale differentiate into red blood cells in vivo. Nat Biotechnol 2002;20(05):467-472

11 Leberbauer C, Boulmé F, Unfried G, Huber J, Beug H, Müllner EW. Different steroids co-regulate long-term expansion versus terminal differentiation in primary human erythroid progenitors. Blood 2005;105(01):85-94

12 Dolznig H, Kolbus A, Leberbauer C, et al. Expansion and differentiation of immature mouse and human hematopoietic progenitors. Methods Mol Med 2005;105:323-344

13 Carotta S, Pilat S, Mairhofer A, et al. Directed differentiation and mass cultivation of pure erythroid progenitors from mouse embryonic stem cells. Blood 2004;104(06):1873-1880

14 Migliaccio AR, Whitsett C, Migliaccio G. Erythroid cells in vitro: from developmental biology to blood transfusion products. Curr Opin Hematol 2009;16(04):259-268

15 Migliaccio G, Sanchez M, Masiello F, et al. Humanized culture medium for clinical expansion of human erythroblasts. Cell Transplant 2010;19(04):453-469

16 Migliaccio G, Masiello F, Tirelli V, et al. Under HEMA conditions, self-replication of human erythroblasts is limited by autophagic death. Blood Cells Mol Dis 2011;47(03):182-197

17 England SJ, McGrath KE, Frame JM, Palis J. Immature erythroblasts with extensive ex vivo self-renewal capacity emerge from the early mammalian fetus. Blood 2011;117(09):2708-2717

18 Baek EJ, Kim HS, Kim S, Jin H, Choi TY, Kim HO. In vitro clinicalgrade generation of red blood cells from human umbilical cord blood CD34+ cells. Transfusion 2008;48(10):2235-2245

19 Flygare J, Rayon Estrada V, Shin C, Gupta S, Lodish HF. HIF1alpha synergizes with glucocorticoids to promote BFU-E progenitor self-renewal. Blood 2011;117(12):3435-3444

20 Lee JCM, Gimm JA, Lo AJ, et al. Mechanism of protein sorting during erythroblast enucleation: role of cytoskeletal connectivity. Blood 2004;103(05):1912-1919

21 Lee HY, Gao X, Barrasa MI, et al. PPAR- $\alpha$ and glucocorticoid receptor synergize to promote erythroid progenitor self-renewal. Nature 2015;522(7557):474-477

22 The European Collection of Cell Cultures Handbook (Online) Accessed August 1, 2018 at https://www.phe-culturecollections.org.uk/media/101902/ecacc_lab_handbook.pdf

23 Javed R, Tilley L, Frayne J, Crew V. Extended blood group genotyping of immortalized erythroid cell line BEL-A2 using next generation whole exome sequencing. Vox Sang 2019;114(Suppl 1):26

24 NHS Blood and Transplant- Clinical Trials Unit. RESTORE 2021. Accessed June 30, 2021 at: https://www.nhsbt.nhs.uk/clinicaltrials-unit/current-trials-and-studies/restore/

25 Housler GJ, Miki T, Schmelzer E, et al. Compartmental hollow fiber capillary membrane-based bioreactor technology for in vitro studies on red blood cell lineage direction of hematopoietic stem cells. Tissue Eng Part C Methods 2012;18(02):133-142

26 Seo Y, Shin KH, Kim HH, Kim HS. Current advances in red blood cell generation using stem cells from diverse sources. Stem Cells Int 2019;2019:9281329

27 Hawksworth J, Satchwell TJ, Meinders M, et al. Enhancement of red blood cell transfusion compatibility using CRISPR-mediated erythroblast gene editing. EMBO Mol Med 2018;10(06):e8454

28 Anstee DJ, Gampel A, Toye AM. Ex-vivo generation of human red cells for transfusion. Curr Opin Hematol 2012;19(03):163-169

29 Douay L, Andreu G. Ex vivo production of human red blood cells from hematopoietic stem cells: what is the future in transfusion? Transfus Med Rev 2007;21(02):91-100

30 Timmins NE, Nielsen LK. Blood cell manufacture: current methods and future challenges. Trends Biotechnol 2009;27(07):415-422

31 Zeuner A, Martelli F, Vaglio S, Federici G, Whitsett C, Migliaccio AR. Concise review: stem cell-derived erythrocytes as upcoming players in blood transfusion. Stem Cells 2012;30(08):1587-1596 